\title{
ANALISIS PENGENDALIAN PERSEDIAAN BAHAN BAKU KAYU PADA UD RAHMA
}

\author{
VITRIA ZAIN \\ SAHARUDDIN KASENG \\ HUSEIN HI. MOH.SALEH \\ Program Studi S 1 Manajemen, Fakultas Ekonomi, Universitas Tadulako \\ Email: zain.vitria@yahoo.com; saharuddin.kfamily@yahoo.com; huseinsaleh868@ gmail.com;
}

\begin{abstract}
Abstrak
Research this purpose find out optimal amount raw material puchases each time making and order, knowing the safety stok raw materials that must be provided and knowing when to re-order raw materials. This type of research is quantitative descriptif research, using the EOQ method of economical raw material purchase in 2017 is 63,67 $\mathrm{m}^{3}$. With the order frequency of 9,14 time and the optimum cycle time of each order is 31,1 days. The number of safety suppies that must be povided is $7.113,6 \mathrm{~m}^{3}$. The right time to re-order is when the raw material supply is $7.121,08 \mathrm{~m}^{3}$.
\end{abstract}

Keywords: Pengendalian Persediaan

\begin{abstract}
Abstrak
Penelitian ini bertujuan untuk menganalisis pembelian bahan baku setiap kali melakukan pemesanan, mengetahui persediaan pengaman bahan baku yang harus disediakan dan mengetahui kapan akan dilakukan pemesanan kembali. Hasil penelitian ini menunjukan dengan menggunakan metode EOQ pembelian bahan baku yang ekonomis tahun 2017 adalah 63,67 $\mathrm{m}^{3}$ dengan frekuensi pemesanan sebayak 9,14 kali dan waktu siklus optimum setiap pemesanan adalah 31,1 hari. Jumlah persediaan pengaman yang harus disediakan adalah $7.113,6 \mathrm{~m}^{3}$. Waktu yang tepat untuk mengadakan pemesanan ulang adalah pada saat persediaan mencapai 7.121,08 $\mathrm{m}^{3}$.
\end{abstract}

Kata Kunci: Pengendalian Persediaan

\section{PENDAHULUAN}

Perkembangan industri kayu yang semakin meningkat menyebabkan permintaan kayu yag semakin bertambah tinggi. Pada mulanya pengusahaan hasil hutan di indonesia ialah sebatas pengusahaan kayu bulat.

Industri penggergajian kayu tergolong dalam industri pengolahan kayu hulu dimana industri ini memanfaatkan bahan baku kayu bulat untuk kemudian diolah menjadi kayu gergajian yang merupakan barang setengah jadi yang kemudian dimanfaatkan lebih lanjut di industri lainnya. Meningkatnya industri pengolahan kayu, dapat meningkatkan nilai tambah kayu bulat yang telah diproduksi agar dapat membuka lapangan pekerjaan bagi rakyat.

Data pembelian bahan baku kayu UD RAHMA tahun 2017, Setiap bulan terjadi beberapa kali transaksi pembelian/ pemesanan kayu. Pembelian kayu setiap bulan tidak menentu. UD RAHMA melakukan pemesanan kayu dengan frekuensi 35 kali setahun. Total pembelian kayu dalam sehari maksimal $28 \mathrm{~m} 3$ dan minimal $11 \mathrm{~m} 3$. UD RAHMA mempunyai duajenis kayu, yaitu kayu merah (Bayur) dan kayu putih (Binuang). Menggunakan metode Economic Order Quantity dalam menentukan total pembelian kayu di Desa Malei Kecamatan Balaesang Tanjung Kabupate Donggala menggunakan mobil truk dan pemuatan barang tersebut maksimal 2 kali dalam 24 jam. Dan lead time (waktu tunggu) pemesanan kayu yaitu 4 hari.

Tabel 1.1 Data Pemesanan Kayu Pada UD RAHMA Tahun 2017

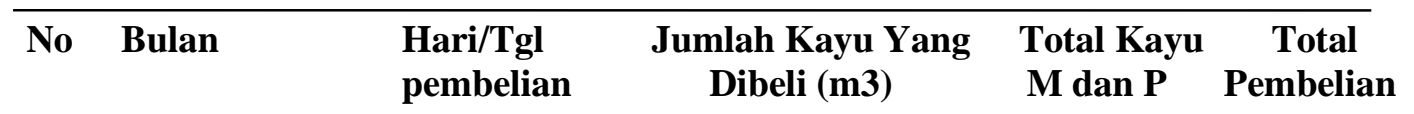




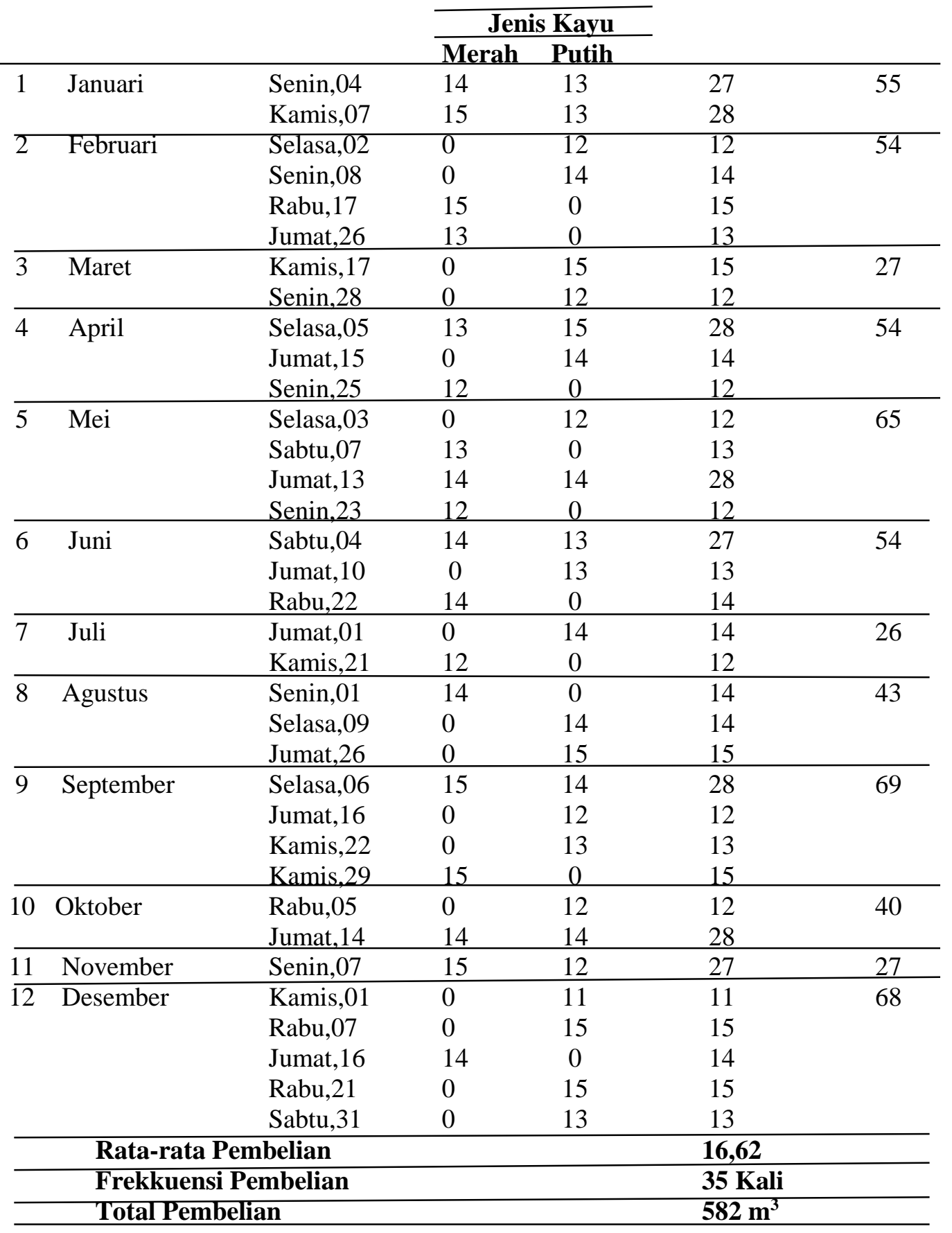

\section{KAJIAN LITERATURE DAN PENGEMBANGAN HIPOTESIS}

Menurut Rangkuti (2004:1) persediaan adalah suatu kegiatan perusahaan dengan maksud untuk proses produksi yang masih dalam pengerjaan atau persediaan yang masih menunggu pelaksanaannya dalam suatu proses produksi.

Menurut Kusuma (2009:132) persediaan yaitu barang yang telah disediakan.

Menurut Ishak (2010:164) memiliki tujuan pengendalian persediaan yaitu:

1. Pasar ingin melayani pelanggan/ konsumen dengan cepat,karena ingin mencapai persediaan yang maksimal. 
2. Produksi ingin beroperasi secara optimal. Pesanan produksi yang tinggi akan menghasilkan persediaan yang besar, persediaan bahan baku/ komponen yang cukup agar proses produksi lancar dan tidak terganggu akibat kurangnya bahan baku.

3. Pembelian. Pembelian menginginkan persediaan sebagai penghalang atas kenaikan harga dan kekurangan produk.

4. Keuangan. Mengecilkan investasi persediaan karena adanya efek negatif dan biaya investasi yang timbul akibat adanya perhitungan pengambilan asset perusahaan.

5. Personalia. Adanya persediaan untuk menjaga naik turunnya kebutuhan.

6. manipulasi. Persediaan yang sedikit agar dapat menjaga ketika terjadi perubahan rekayasa.

Menurut Assauri (2004:176) pengendalian persediaan yaitu suatu kegiatan yang saling besangkutan satu sama lain dalam suatu operasi produksi perusahaan yang sesuai dengan perencanaan baik dalam waktu, jumlah, kuantitas, dan biaya.

Menurut Fahmi (2014:120) Economic order Quantity (EOQ) yaitu metode yang digunakan oleh perusahaan dengan menentukan jumlah barang yang harus dipesan dengan biaya persediaan yang lebih optimal.

Menurut Ahyari (1986:160) unsur-unsur EOQ yaitu:

a. Biaya simpan

b. Biaya pesan

c. Persediaan

d. Harga pembelian

Menurut Ahyari (1986:163). Adapun faktor-faktor yang mempengaruhi proses produksi yaitu:

1. Asumsi penggunaan persediaan

Banyaknya total biaya persediaan yang telah digunakan perusahaan untuk kelancaran produksi diperlukan rencana dan jadwal.

2. Harga bahan baku

Harga bahan baku yang digunakan dalam proses produksi dalam perusahaan, karena harga bahan baku yang digunakan perusahaan dalam penyelenggarraan persediaan dalam jumlah unit.

3. Biaya-biaya persediaan

Biaya-biaya persediaan telah ditanggung oleh perusahaan, ada 3 macam biaya ialah biaya simpan, biaya pesan, dan biaya tetap.

4. Kebijaksanaan pembelanjaan

Kebijaksanaan pembelanjaan perusahaan telah mempengaruhi seluruh kebijaksanaan pembelian dalam perusahaan yang bersangkutan.

5. Penggunaan bahan baku

Penggunaan bahan baku oleh perusahaan yang bersangkutan dalam suatu periode untuk keperluan proses produksi yang digunakan sebagai dasar pertimbangan penyelenggaraan bahan baku.

6. Waktu tunggu

Waktu tunggu merupakan waktu yang diperlukan pada saat pemesanan sampai datangnya bahan baku.

7. Tehnik pembelian bahan

Model pembelian bahan yang digunakan perusahaan menentukan besar kecilnya persediaan bahan baku didalam perusahaan. Model pembelian yang berbeda dapat menghasilkan pembelian yang maksimal dan berbeda.

8. Persediaan pengaman

Penting bagi perusahaan untuk mengadakan persediaan pengaman.

9. Pembelian kembali

Proses produksi dalam suatu perusahaan tidak akan mencukupi apabila dilakukan dengan sekali pembelian.

Menurut Hanggana (2006:11) bahan baku yaitu suatu barang yang digunakan untuk membuat barang setengah jadi menjadi barang jadi.

Menurut Broto (2002:52) arti bahan baku yaitu barang-barang yang terwujud seperti: 
a. besi

b. cengkeh

c. kain.

Menurut Heizer dan Barry (2010:92) metode pengendalian persediaan digunakan berdasarkan perkiraan ialah:

1. Total biaya

2. Lead time

3. Penerimaan persediaan bersifat instant

4. Tidak menerima potongan harga

5. Biaya variabel hanya biaya untuk menyimpan atau melakukan pemesanan

6. Biaya penyimpanan berjangka

7. Kekurangan bahan

Menurut petty, Willyam, Scott dan David (2005:278) asumsi-asumsi dalam EOQ (Ecinomic Order Quantity) yaitu:

1. Permintaan konstan merupakan permintaan yang sama/seragam dengan model EOQ mengasumsikan bahwa permintaan konstan/sesungguhnaya dapat bervaiasi.

2. Harga perunit konstan dengan adaya diskon kuantitas dapat lebih mudah ditangani dengan cara memfariasikannya dan mendefinisikan total biaya yang akan menentukan pesanan.

3. Biaya penyimpanan konstan yaitu biaya yang biayanya berfariasi ketika persediaan meningkat.

4. Biaya pemesanan konstan yaitu dengan memfariasikan model EOQ sehingga dapat digunakan jumlah unit.

5. Pengiriman mendadak yaitu ketika andanya pengiriman tiba-tiba maka harus memesan stock pengaman.

6. Pemesanan independen yaitu biaya administrasi dan transportasi maka harus dengan tehnik Economic Order Quantity memfariasikan kembali karena multi pesan menghasilkan penghemat biaya.

Faktor-faktor mempengaruhi safety stock yaitu:

1. Risiko kehabisan persediaan, ditentukan:

a) Telah di tetapkan dalam kontrak pembelian bahwa pengiriman barang yang telah dipesan apakah sering kali lambat dari waktu yang telah di disepakati atau tepat pada waktunya. Kebiasan supplier dalam pengiriman barang yang dipesan sesuai dengan waktu yang telah disepakati maka perusahaan harus memiliki persediaan yang cukup besar.

b) Dapat diduga/tidaknya kebutuhan bahan baku/penolong produksi. Jika kebutuhan bahan baku/penolong untuk produksi dapat diduga maka perusahaan tidak harus memiliki persedian yang besar.

2. Biaya simpan digudang dan biaya ekstra bila kehabisan persediaan. Jika di bandingkan biaya penyimpanan gudang lebih besar dari biaya pesanan ekstra, maka perusahaan tidak harus memili persediaan yang besar.

3. Sifat persaingan. Persaingan antar perusahaan terjadi/dapat ditentukan dari kecepatan pelayanan/ pemenuhan keingan dari pelanggan/konsumen, maka perusahaan perlu memiliki persediaan yang cukup besar.

Menurut fahmi (2014:120) tiga bentuk variabel EOQ yaitu:

1. Total cost/ total biaya merupakan seluruh jumlah biaya yang telah diperhitungkan.

2. Ordering cost/ biaya pesanan yaitu seluruh biaya yang telah diperhitungkan selama dalam proses pembelian

3. Cerrying cost/biaya peyimpanan merupakan biaya-biaya yang diperhitungkan sehubungan dengan adanya penyimpanan.

\section{Kerangka Pemikiran}

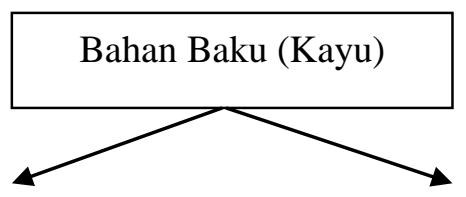




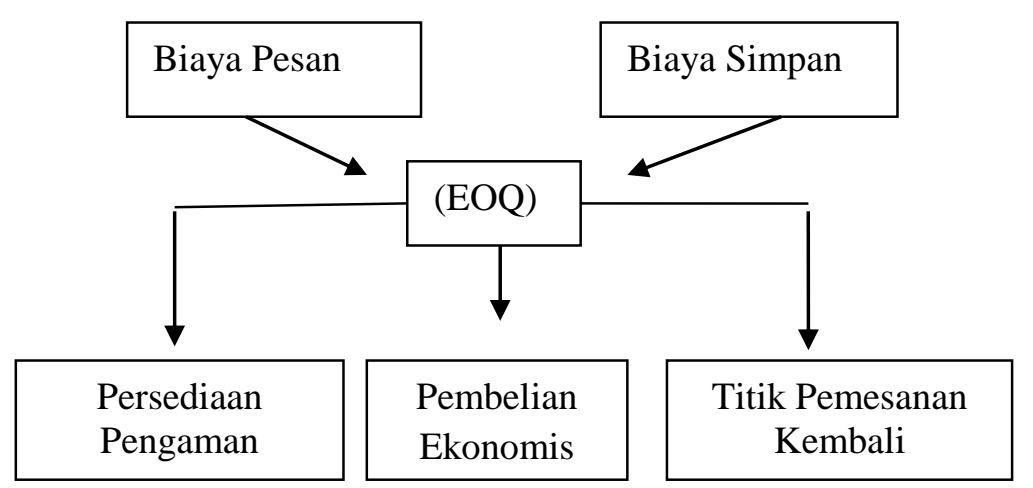

Gambar 1. Kerangka fikir

\section{METODE PENELITIAN}

Menurut Azwar (2012) metode deskriptif yaitu menyajikan/menganalisis fakta secara menyeluruh sehingga dapat lebih mudah di pahami/disimpulkan. Penelitian ini yaitu penelitian kuantitatif yaitu data yang berbetuk angka/bilangan, sesuai dengan bentuknya sehingga dapat diolah/dianalisis dengan menggunakan perhitungan statistika.

Lokasi penelitian yaitu pada UD RAHMA yang bergerak dibidang idustri kayu jadi. Berlokasi di Desa Dalaka kecamatan Sindue Kabupaten Donggala. Alasan peneliti meneliti Sawmill UD RAHMA karena perusahaan UD RAHMA belum menetapkan kebijakan pembelian bahan baku kayu dan belum mementukan persediaan pengaman dan titik pemesanan kembali.

Tehnik pengumpulan data yaitu:

1. Wawancara ialah untuk mendapatkan data yang dibutuhkan dilakukan wawancara secara langsung kepada beberapa pihak, diantaranya: Pemimpin dan Manajer UD RAHMA.

2. Observasi yaitu pengamatan secara langsung dilakukan untuk mendapatkan data-data mengenai isi perusahaan.

3. Dokumentasi ialah tehnik dengan mengumpulkan sejumlah data berupa dokumentasi tertulis yang dimiliki perusahaan yang berkaitan dengan permasalahan.

\section{Metode Analisis Data}

Metode analisis yang digunakan dalam penelitian ini adalah metode kuantitatif yang digunakan untuk memecahkan permasalahan secara sistematis.

\section{Menentukan Economic Order Quantity (EOQ)}

Model persediaan Economic Order Quantity ialah total dari persediaan dengan meminimalkan biaya agar menjadi ekonomis.. Menurut Fahmi (2014) rumus menghitung EOQ (Economic Order Quantity) yaitu:

\section{Keterangan:}

$$
E O Q=\frac{\sqrt{2(\mathrm{D})(\mathrm{OC})}}{\mathrm{CC}}
$$

$\mathrm{EOQ}=$ Economic Order Quantity

$\mathrm{D} \quad=$ Permintaan tahunan (demand)

$\mathrm{OC}=$ Biaya Pemesanan (Ordering Cost)

OC = Biaya peyimpanan $($ Carrying Cost)

Rumus untuk menghitung frekuensi pembelian optimal yaitu:

$$
\mathrm{F}=\frac{\mathrm{D}}{\mathrm{Q}}
$$

Keterangan:

$\mathrm{F}=$ Frekuensi pembelian 
$\mathrm{D}=$ Jumlah pembelian (permintaan) selama satu periode

$\mathrm{Q}=$ Jumlah barang pada setiap pesanan

Rumus menghitung waktu siklus optimum yaitu:

$$
\mathrm{T}=\frac{Q}{D}
$$

Keteragan:

$\mathrm{T}=$ Waktu pembelian

$\mathrm{Q}=$ Jumlah barang pada setiap pesanan

$\mathrm{D}=$ Jumlah pembelian (permintaan) selama satu periode

Menentukan Reorder Point ( ROP)

Menurut (Heizer dan Barry,21011:75) reorder point dapat dihitung dengan rumus berikut:

$$
\mathrm{ROP}=(\mathrm{dL})+\text { Safety stock }
$$

Keterangan:

ROP = Titik pemesanan kembali

$\mathrm{d} \quad=$ Pemakaian bahan baku perhari (unit/hari)

$\mathrm{L} \quad=$ Waktu tunggu

SS = Persediaan pengaman

Persediaan Pengaman ( Safety Stock )

Menurut Fahmi (2014:121) safety stock dapat dihitung dengan rumus berikut:

$$
\mathrm{SS}=\mathrm{SD} \text { X Z }
$$

Keterangan:

SS = persediaan pengaman (safety stock)

$\mathrm{SD}=$ Standar Deviasi

$\mathrm{Z}=$ Faktor keamanan ditentukan atas dasar kemampuan perusahaan.

\section{HASIL DAN PEMBAHASAN}

Total biaya persediaan bahan baku kayu pada UD RAHMA terdiri atas biaya pesanan dan biaya penyimpanan.

a) Biaya pemesanan yaitu biaya yang dikeluarkan karena adanya pemesanan bahan baku dari supplier.

Biaya yang ditanggung oleh perusahaan UD RAHMA yaitu:

1) Biaya telepon yaitu biaya yang timbul karena adanya pemakaian jasa komunikasi untuk transaksi pemesanan bahan baku. Biaya telepon tahun 2017 sebesar Rp280.000.

2) Biaya trasportasi yaitu biaya yang dikeluarkan perusahaan utuk melakukan proses transportasi. Biaya transportasi pada tahun 2017 yaittu sebesar Rp10.500.000

3) Biaya bongkar yaitu biaya yang ada akibat kegiatan memuat dan membongkar kayu dari atas truk. Biaya bongkar pada tahun 2017 yaitu sebesar Rp3.500.000

4) Biaya administrasi yaitu biaya yang terjadi karena perusahaan melakukan transaksi pembayaran dan pembelian bahan baku kayu serta pembukuan pembelian bahan baku. Biaya administrasi yang dikeluarkan untuk pembelian bahan baku yaitu sebesar Rp350.000.

Tabel 1. Biaya Pemesanan Tahun 2017

\begin{tabular}{llr} 
Jenis Biaya & \multicolumn{2}{l}{ Biaya } \\
\hline BiayaTelepon & $\mathrm{Rp}$ & 280.000 \\
Biaya Transportasi & $\mathrm{Rp}$ & 10.500 .000 \\
Biaya Administrasi & $\mathrm{Rp}$ & 350.000 \\
Biaya Bongkar & $\mathrm{Rp}$ & 3.500 .000 \\
\hline Total Biaya Pemesanan Pertahun & $\mathbf{R p}$ & $\mathbf{1 4 . 6 3 0 . 0 0 0}$ \\
Biaya pemesanan Sekali Pesan & $\mathbf{R p}$ & $\mathbf{4 1 8 . 0 0 0}$ \\
\hline Sumber: Bagian Keuangan UD RAHMA & \multicolumn{2}{l}{}
\end{tabular}

Biaya pemesanan kayu

Total biaya Rp 14.630 .000 
Frekuensi pemesanan 35 kali dalam 1 tahun

Biaya pemesana $=$ Total biaya pemesanan : Frekuensi pemesanan

$$
\begin{aligned}
& =\operatorname{Rp~14.630.000:35~} \\
& =\operatorname{Rp~418.000/~unit~}
\end{aligned}
$$

b) Biaya penyimpanan yaitu biaya yang timbul karena adanya biaya penyimpanan yang dilakukan perusahaan. Adapun biaya simpan yang dikeluarkan perusahaan UD RAHMA ialah:

1) Biaya gudang tidak ada karena gudang milik perusahaan. Biaya yang timbul yaitu biaya pemeliharaan dan biaya susut gudang.

a) Biaya pemeliharaan gudang pada tahun 2017 sebesar Rp1.500.000

b) Biaya penyusutan gudang yaitu biaya yang ada karena penurunan nilai suatu gudang. Biaya penyusutan gudang sebesar Rp500.000 selama tahun 2017.

2) Biaya listrik yaitu biaya yang digunakan karena adanya pemakainan listrik bagian gudang perusahaan sebesar Rp2.200.000 selama tahun 2017.

Tabel 2. Biaya Penyimpanan Tahun 2017

\begin{tabular}{lcr}
\hline Jenis Biaya & Biaya \\
\hline Biaya Pemeliharaan & $\mathrm{Rp}$ & 1.500 .000 \\
Biaya penyusutan & $\mathrm{Rp}$ & 500.000 \\
Biaya Listrik & $\mathrm{Rp}$ & 2.200 .000 \\
\hline Total Biaya Penyimpanan Pertahun & $\mathbf{R p}$ & $\mathbf{4 . 2 0 0 . 0 0 0}$ \\
\hline Biaya penyimpanan Sekali Pesan & $\mathbf{R p}$ & $\mathbf{7 . 2 1 6}$ \\
\hline Sumber: Bagian Keuangan UD RAHMA &
\end{tabular}

Biaya penyimpanan Kayu

Total biaya Simpan Rp 4.200.000

Jumlah kebutuhan bahan baku $582 \mathrm{~m}^{3}$

Biaya penyimpanan $=$ total biaya simpan : kebutuhan bahan baku

$$
\begin{aligned}
& =\operatorname{Rp} 4.200 .000: 582 \\
& =\operatorname{Rp~} 7.216 \mathrm{~m}^{3}
\end{aligned}
$$

Agar dapat meghitung biaya menggunakan metode EOQ yang diperlukan oleh perusahaan:

a) Jumlah pembelian (permintaan) selama satu periode (D) $=582 \mathrm{~m}^{3}$

b) Biaya simpan tahunan dalam rupiah/unit $(\mathrm{CC})=\mathrm{Rp} 4.200 .000$

c) Biaya Pemesanan tahunan (OC) $=$ Rp 14.630 .000

Total pembelian bahan baku kayu yang ekonomis menggunakan metode EOQ yaitu:

$$
\begin{aligned}
E O Q & =\frac{\sqrt{2(\mathrm{D})(\mathrm{OC})}}{C C} \\
& =\frac{\sqrt{2(582)(\mathrm{Rp} 14.630 .000)}}{\operatorname{Rp} 4.200 .000} \\
& =\frac{\sqrt{17.029 .320 .000}}{\operatorname{Rp} 4.200 .000} \\
& =\sqrt{4.054,6} \\
& =63,67 \mathrm{~m}^{3}
\end{aligned}
$$

1) Total Biaya Tahun minimum (TIC)

$$
\mathrm{TIC}=\left(\frac{D}{Q}\right) \mathrm{oc}+\left(\frac{Q}{2}\right) \mathrm{cc}
$$




$$
\begin{aligned}
& =\left(\frac{582}{63,67}\right) \operatorname{Rp} 14.630 .000+\left(\frac{63,67}{2}\right) \operatorname{Rp} 4.200 .000 \\
& =\operatorname{Rp~133.731.113,5~}+\operatorname{Rp~133.707.000~} \\
& =\operatorname{Rp} 267.438 .113,5
\end{aligned}
$$

2) Total Pemesanan Tahunan (TOC)

$$
\begin{aligned}
\text { TOC } & =\left(\frac{D}{Q}\right) \text { oc } \\
& =\left(\frac{582}{63,67}\right) \operatorname{Rp} 14.630 .000 \\
& =\operatorname{Rp} 133.731 .113,5
\end{aligned}
$$

3) Total Biaya Simpan Tahunan (TCC)

$$
\begin{aligned}
\text { TCC } & =\left(\frac{Q}{2}\right) c c \\
& =\left(\frac{63,67}{2}\right) \quad \operatorname{Rp} 4.200 .000 \\
& =\operatorname{Rp} 133.707 .000
\end{aligned}
$$

4) Frekuensi pemesanan optimum (F)

$$
\begin{aligned}
\mathrm{F} & =\frac{\mathrm{D}}{Q} \\
& =\frac{582}{63,67} \\
& =9,14 \mathrm{kali}
\end{aligned}
$$

5) Jarak siklus optimum (T)

$$
\begin{aligned}
\mathrm{T} & =\frac{\mathrm{Q}}{D} \\
& =\frac{63,67}{582} \\
& =0,10(311) \\
& =31,1 \text { hari }
\end{aligned}
$$

Jadi dalam 1 tahun 311 hari kerja, maka waktu siklus optimum setiap pemesanan adalah $\mathrm{T}=0,10$ $(311)=31,1$ hari.

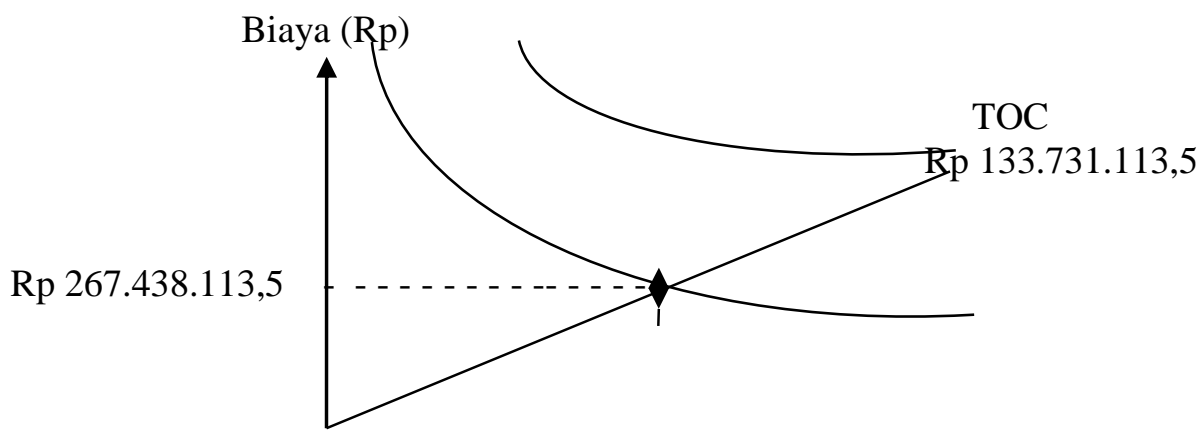




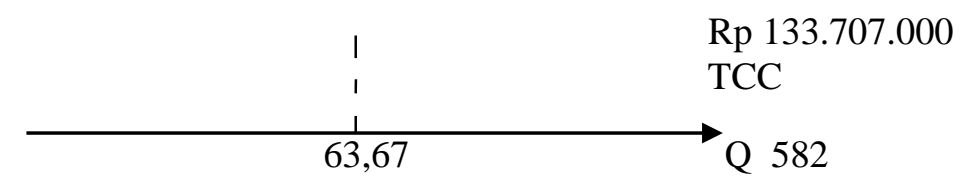

Gambar 2. Biaya persediaan Berdasarkan Metode EOQ Tahun 2017

Tabel 3. Standar Deviasi

\begin{tabular}{lcccc}
\hline Bulan & $\mathbf{x}$ & $\mathbf{x}$ & $\mathbf{( x - x )}$ & $\mathbf{( x - \mathbf { x } ) ^ { \mathbf { 2 } }}$ \\
\hline Januari & 55 & 16,62 & 38,38 & $1.473,02$ \\
Februari & 54 & 16,62 & 37,38 & $1.397,26$ \\
Maret & 27 & 16,62 & 10,38 & 108 \\
April & 54 & 16,62 & 37,38 & $1.397,26$ \\
Mei & 65 & 16,62 & 48,38 & 2.341 \\
Juni & 54 & 16,62 & 37,38 & $1.397,26$ \\
Juli & 26 & 16,62 & 9,38 & 88 \\
Agustus & 43 & 16,62 & 26,38 & 696 \\
September & 69 & 16,62 & 52,38 & 2.744 \\
Oktober & 40 & 16,62 & 23,38 & 547 \\
November & 27 & 16,62 & 10,38 & 108 \\
Desember & 68 & 16,62 & 51,38 & 2.640 \\
\hline Total & $\mathbf{5 8 2}$ & $\mathbf{1 9 9 , 4 4}$ & $\mathbf{3 8 2 , 5 6}$ & $\mathbf{1 4 . 9 3 5}$ \\
\hline & & & &
\end{tabular}

Service level menentukan standar deviasi ialah 1,65. Standar deviasi yaitu:

$$
\begin{aligned}
\mathrm{SD} & =\frac{\sqrt{\sum(\mathrm{x}-\mathrm{x}) 2}}{\mathrm{~N}} \\
\mathrm{SD} & =\frac{\sqrt{14.935}}{12} \\
\mathrm{SD} & =4.311,3
\end{aligned}
$$

Cara menentukan jumlah persediaan pengan yaitu:

$$
\begin{aligned}
\mathrm{SS} & =\mathrm{SDXZ} \\
& =4.311,3 \times 1,65 \\
& =7.113,6 \mathrm{~m}^{3}
\end{aligned}
$$

Jadi, dapat disimpulkan bahwa safety stock selama tahun 2017 adalah 7.113,6 $\mathrm{m}^{3}$

Menghitung ROP dengan menggunakan rumus:

$\mathrm{ROP}=(\mathrm{dL})+$ Safety stock

Keterangan:

- Re Order Point (ROP)

- Kebutuhan bahan baku (d)

- Waktu tunggu (L)

- Persediaan pengaman (SS)

Selisih waktu antar pesanan kayu yaitu 4 hari, perusahaan melakukan pemesanan ulang yaitu:

- Waktu tunggu (L)

- Persediaan Pengaman (SS)

- Jumlah hari kerja dalam satu tahun

$$
\begin{aligned}
& =4 \text { hari } \\
& =7.113,6 \\
& =311 \text { hari } \\
& =\frac{582}{311}=1,87 \mathrm{~m}^{3}
\end{aligned}
$$

$\mathrm{ROP}=(\mathrm{dL})+\mathrm{SS}$ 


$$
\begin{aligned}
& =(4 \times 1,87)+7.113,6 \\
& =7,48+7.113,6 \\
& =7.121,08 \mathrm{~m}^{3}
\end{aligned}
$$

Jadi dapat disimpulkan reorder point selama tahun 2017 adalah 7.121,08 $\mathrm{m}^{3}$ Pola persediaan UD RAHMA dengan kebijakan yang baru dapat dilihat dalam Gambar 3

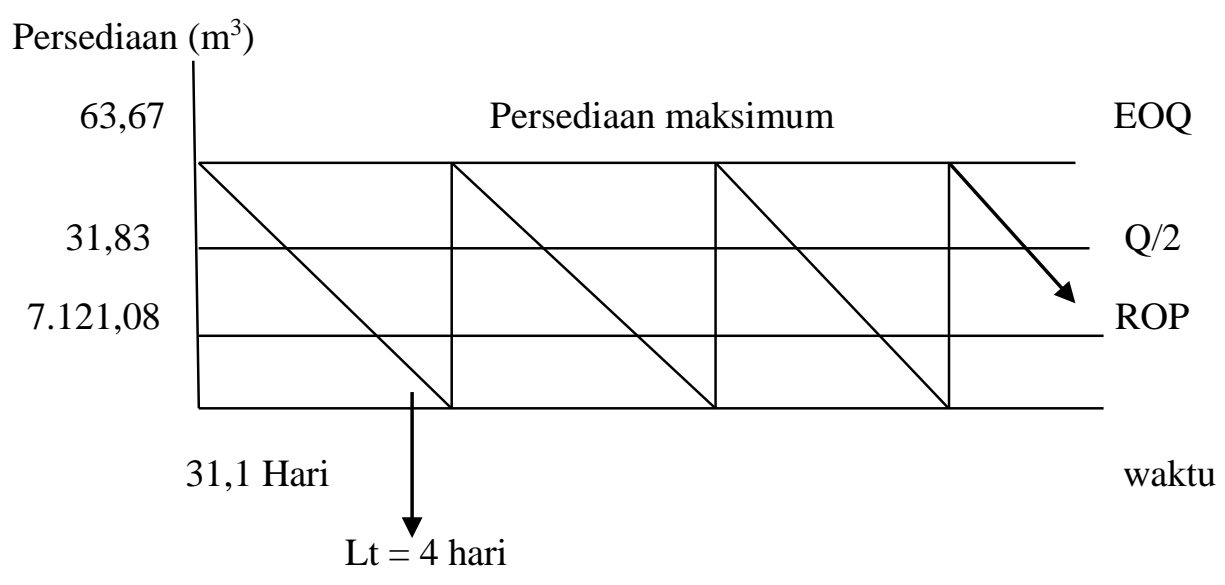

Gambar 3. Persediaan UD RAHMA Tahun 2017

\section{PENUTUP}

Peneliti menyimpulhan hasil penelitian menggunakan metode Economic Order Quantity(UD RAHMA) yaitu:

a) Hasil penelitian jumlah pemesanan kayu yang optimal pada UD RAHMA yaitu sebesar 63,67 pada tahun 2017

b) Perusahaan harus melakukan pemesanan kembali sebanyak 9,14 kali dan waktu siklus optimum setiap kali pemesanan adlah 31,1 hari pada tahun 2017.

c) Hasil penelitian jumlah persediaan kayu perusahaan dengan menggunakan metode Economic Order Quantity yaitu Rp267.438.113,5.

d) Jumlah persediaan pengaman yang harus dikeluarkan perusahaan yaitu sebesar 7.113,6 $\mathrm{m}^{3}$

e) Hasil penelitian sebaiknya UD RAHMA melakukan pemesanan ulang yaitu $7.121,8 \mathrm{~m}^{3}$

Berdasarkan hasil wawancara, penulis mengajukan saran-saran kepada pihak UD RAHMA. Adapun saran-saran yaitu:

a) UD RAHMA seharusnya memperhatikan jenis-jenis biaya yang timbul akibat adanya biaya pemesanan dan penyimpanan, karena jenis-jenis biaya tersebut sangat penting bagi kelangsungan perusahaan.

b) UD RAHMA seharusya memakai tekhnik/metode Economic Order Quantity, dengan memakai metode tersebut jumlah persediaan bahan baku menjadi minimal/efisien

c) UD RAHMA harus menentukan persediaan pengaman dan titik pemesanan kembali agar dapat menanggulangi jika terjadi kekurangan bahan baku dan terlambatnya pemesanan bahan baku.

\section{REFERENSI}

Ahyari, Agus, 1986. Manajemen Produksi Pengendalian Produksi. Buku satu Edisi keempat, BPFE, Yogyakarta.

Assauri, Sofyan, 2004. Manajemen Produksi dan Operasi, CP-FEUI Jakarta

Azwar, S. 2012. Metode Penelitian. Pelajar Pustaka : Yogyakarta

Fahmi, Irham, 2014. Manajemen Produksi dan Operasi Cetakan Ketiga, Alfabeta, Bandung.

Hanggana, Sri. 2006. Prinsip Dasar Akuntansi Biaya, Mediatama, Surakarta. 
Heizer, Jay dan Barry Render. 2011. Operations Management Buku 1 Edisi kesembilan, Salemba Empat, Jakarta.

Ishak, Aulia. 2010. Manajemen Operasi Edisi Pertama, Graha Ilmu, Yogyakarta.

Kusuma, Hendra. 2009. Manajemen Produksi Perencanaan dan Pengendalian Produksi, Edisi Keempat, Andi, Yogyakarta

Petty, William, Scott, dan David. 2005. Finance Management, Prentice Hall, New Jersey.

Rangkuti, F. 2004. Manajemen Persediaan Aplikasi dibidang Bisnis Penerbit Erlangga, Jakarta. 